\title{
Tractor ROPS and Stability Research: Introduction to this Special Issue
}

\author{
P. D. Ayers, V. Rondelli
}

A gricultural production has clearly benefited from the development of the tractor. The tractor provides a traction device and mobile power source. However, operating large equipment with high clearance on uneven ground leads to stability and overturn issues. Around the world, tractor overturns are still a leading cause of agricultural production fatalities.

This special issue of the Journal of Agricultural Safety and Health focuses on recent research on tractor ROPS (rollover protective structures) and stability. Engineers and scientists in both Italy and the U.S. have been working on these topics, attempting to solve old problems and address rising issues. Understanding the factors leading to tractor instability, investigating the structures protecting the operator, and examining the continuous roll potential will all lead to increased operator protection and reduced fatalities.

The initial driving force to combine the efforts of Italian and U.S. investigators was a meeting of those interested in ROPS and stability research at the September 2012 SHWA (Safety, Health, and Welfare in Agriculture and in Agro-food Systems) meeting in Ragusa, Sicily, hosted by Giampaolo Schillaci of the University of Catania. Scientists and engineers from the U.S. and Italy met to share common interests related to tractor ROPS and stability research. In October, 2013, a tractor ROPS and stability research forum, hosted by Dr. Valda Rondelli, was held in Bologna, Italy, following the 2013 OECD Test Engineers Conference. This led to a special tractor ROPS and stability research session at the International Conference on Rural Health and Ragusa SHWA on 8-11 September, 2015, in Lodi, Italy. Although the presentations were valuable, the presenters and colleagues felt that a special issue of the Journal of Agricultural Safety and Health focusing on the pertinent problems was needed to (1) update the research activities and (2) document the efforts to a broader audience. Thus, this special issue was developed.

If a rollover can be avoided or prevented, then operator protection is improved. The first two articles in this special issue focus on tractor stability:

Evaluation of a Commercial Tractor Safety Monitoring System Using a Reverse Engineering Procedure (C. Casazza, R. Martelli, and V. Rondelli, University of Bologna; doi 10.13031/jash.22.11667) describes an innovative method of acquiring tractor stability data from a commercial driver assist device. The tractor operating

\footnotetext{
Submitted for review in September 2016 as manuscript number JASH 12127; approved for publication as part of the Tractor ROPS and Stability Research Collection by the Ergonomics, Safety, \& Health Community of ASABE in September 2016.

The authors are Paul D. Ayers, ASABE Member, Professor, Department of Biosystems Engineering and Soil Science, University of Tennessee, Knoxville, Tennessee, and Valda Rondelli, Associate Professor, Department of Agricultural and Food Sciences, University of Bologna, Italy. Corresponding author: Paul D. Ayers, Department of Biosystems Engineering and Soil Science, University of Tennessee, Knoxville, Tennessee; e-mail: ayers@utk.edu.
}

Journal of Agricultural Safety and Health 
characteristics can then be used to define the tractor stability index and identify unstable conditions.

Development of an Open-Source Tractor Driving Simulator for Tractor Stability Tests (N. Ocha Lleras, S. Brennan, D. Murphy, M. J. Klena, P. M. Garvey, and H. J. Sommer III, Pennsylvania State University; doi 10.13031/jash.22.11774) investigates the development of a tractor stability simulator to determine operator perception of stability and approximate slope conditions. Operators tended to underestimate slope conditions.

The third article focuses on a ROPS design procedure to increase ROPS availability:

Development and Evaluation of a Computer-Based ROPS Design Program (P. Ayers, F. Khorsandi, Y. John, and G. Whitaker, University of Tennessee; doi 10.13031/jash.22.11745) describes a simple Excel-based program for developing ROPS designs based on tractor weight and dimensions. Tractor ROPS were designed and tested to meet SAE Standard J2194 static ROPS tests.

If a tractor starts to roll, what are the contributing factors to a continuous roll? The fourth article addresses the behavior of rubber-tracked tractors during a continuous roll:

Effects of Rubber Tracks on Narrow-Track Tractors on the Non-Continuous Rolling Prediction Model (B. Franceschetti, E. Capacci, and V. Rondelli, University of Bologna; doi 10.13031/jash.22.11668) investigates the influence of a tracked tractor on continuous roll potential. The continuous roll model was modified to include the influence of tracks. Tracks increased the ROPS height required to stop a continuous roll when compared to wheels.

What if ROPS are not being used properly? Many tractor operators with foldable ROPS are operating with the ROPS folded down, and the related rollover fatalities are increasing. What are the actuation forces required to raise and lower a foldable ROPS, and are they above the allowable forces? The last two articles focus on the newly developing issue of foldable ROPS:

Narrow-Track Agricultural Tractors: A Survey on the Load of the HandOperated Foldable Rollbar (D. Pessina, D. Facchinetti, and D. M. Giordano, University of Milan: doi 10.13031/jash.22.11709) evaluates the actuation forces for 19 mid-mount foldable ROPS. They found that several ROPS exceeded the allowable ergonomic forces, and a lift assist can dramatically lower the actuation forces.

The Effect of Speed on Foldable ROPS Actuation Forces (F. Khorsandi, P. Ayers, D. Jackson, and J. Wilkerson, University of Tennessee; doi 10.13031/jash.22.11752) investigates the influence of actuation speed on the measured forces and quantifies the influence of friction. Raising forces exerted from a stopped position were higher than the forces exerted during continuous movement. Friction can result in a substantial increase in raising actuation forces but reduces the required lowering resistive forces.

Not only is this new research valuable, but the introduction and literature review in each article provide a significant historical resource. However, the research efforts should not stop here. Research into stability controls to avoid tractor overturns, further evaluation of foldable/deployable ROPS, and finite element analysis to lower ROPS costs are needed. Look for future articles related to these important ROPS and stability research topics in upcoming issues of the Journal of Agricultural Safety and Health. 